\title{
INDUSTRY 4.0 FROM THE POINT OF VIEW OF HUMAN RESOURCES MANAGEMENT
}

\author{
Katarzyna SZYMCZYK \\ Czestochowa University of Technology, Częstochowa, Poland; katarzyna.szymczyk@wz.pcz.pl, \\ ORCID: 0000-0003-0869-2454
}

\begin{abstract}
Purpose: The article discusses the role of the employee in the era of robotization and automation of industry. It outlines potential threats and opportunities for HR management in the age of the fourth industrial revolution.

Design/methodology/approach: The author used a desk research method. She gathered documents (statistic data, mainly reports), made the initial selection, established the authenticity of the data, carried out the study of scientific literature and, eventually, did the comparative analysis.
\end{abstract}

Findings: Industry 4.0 is associated with changes in human resource management. Employees will need to acquire new skills and knowledge to be able to keep a job. Automation and digitalization of business/industry will be an opportunity for self-development and success for people with expertise in IT technology, robotics and computer engineering. Business in the era of Industry 4.0 will need to cope with the ageing population, the lack of proper education and training conditions, and lack of access to new technologies.

Practical implications: The paper analyses the biggest challenge in the aspect of employees adaptation and focuses on problems that exist but must change so that businesses can adapt to the new reality of Industry 4.0.

Originality/value: The paper complements previous research in the field of human resource management in the conditions of the fourth industrial revolution, digitization, digitalization and automation of business.

Keywords: Industry 4.0, HR management, competences, automation, digitalization.

Category of the paper: Research paper.

\section{Introduction}

Digitalization and automation are the core of the concept of Industry 4.0, which is nowadays taking place and increasingly influencing various aspects of business management. Industry 4.0 unquestionably brings challenges and threats in the aspect of human resource management. The future generation of workers will function in the reality of intelligent machine management 
and integration of people and robots. Therefore, the question arises what kind of competences and skills, hard and soft, will be necessary to allow individuals to compete in the labour market with computers and robots. Indeed, it will be the era of a new category of workforce with technical, specialized and often limited knowledge, as well as with highly advanced competences, but at the same with soft and multifaced skills. Factories based on the most advanced computer technologies and cyber systems have for some time been an almost permanent element of the discussion on the image of the industry of tomorrow. The progressive implementation of new technologies into the industry must at the same time involve the reduction of human resources. Computers controlling production processes, robots, digital machines and devices replacing the work of human hands are the result of many decades of innovations introduced into factories. This article deals with issues regarding the vanishing importance of man as a worker and his role as an irreplaceable resource of manufacture enterprises in the era of robotization and automation of production. A hypothesis was put forward that the Industry 4.0, which is based on advanced technologies of production automation, cyber robotics, despite its advantages, is becoming a threat to maintaining workplaces that will be replaced shortly by computers, ingenious devices, smart technologies and robots. To what extent automation, robotics and the computerization of manufacturing will affect the employment of the workforce? Will the human beings be redundant if machines and robots take over their workplaces? What sort of skills and competencies will be required among the workforce? Further discussion in this paper focuses on the concept of Industry 4.0 and the vision of future smart factory which may result in a severe problem of massive unemployment of people whose work so far has been regarded as essential and needed in each manufacturing company.

\section{Findings}

The World Economic Forum in The Future of Jobs Report (2018) claims that shortly, by 2022 , there will be a demand for employees with soft skills corresponding to jobs such as customer service workers, sales and marketing professionals, in training, development, people and culture areas, organizational development specialists, and innovation managers. There will also be the demand for completely new specialists dealing with new technologies, such as AI and machine learning specialists, Big Data specialists, analysts, user experience and human-machine interaction designers, robotics engineers and Blockchain specialists, or process automation and information security experts. Among the job positions which will be terminated are for example accounting, administrative and executive secretaries, assembly and factory workers, accountants and auditors, cashiers and ticket clerks, mechanics and machinery repairers, car, van and motorcycle drivers, vendors, and related workers, statistical, finance and 
insurance clerks and even lawyers. According to the World Bank (2019), the technology integrated within businesses should demand form employees the most wanted skills which are: advanced cognitive skills enabling solving problems, skills that support teamwork - so-called the sociobehavioural abilities, as well as skill combinations associated with the ability to fast adaptation, self-efficacy and the capability of advanced reasoning. Such skills will be fundamental in labour markets. The decline and the growth in employment due to Industry 4.0 will be noticeable (Figure 1).



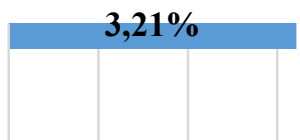

$2,70 \%$

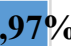

$\mathbf{0 , 7 0 \%}$

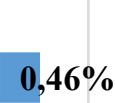

$93 \%$

$03 \%$

$63 \%$

Figure 1. The decline and the growth in employment due to Industry 4.0. Adapted from: "The Future of Jobs. Employment, Skills and Workforce Strategy for the Fourth Industrial Revolution" by The World Economic Forum. Copyright 2016 by Switzerland: World Economic Forum.

The World Economic Forum (2016) report confirms the above information by presenting its survey results which indicate that the labour market can expect the compound growth of employment (2015-2020) in jobs like architecture and engineering (2.7\%) thanks to increasing demand for the specialists in processing power, additive printing, Big Data, cloud computing and Internet of Things, or computer and mathematics $(3.21 \%)$ and management $(0.97 \%)$. To a lesser extent, the minor growth of employment should be noticed in business and financial operations $(0.70 \%)$ or sales and related sectors $(0.46 \%)$ in which the low score is caused by replacing human work by sensor-based smart inventory management and the applications of 
the Internet of Things. The decline is expected in installation and maintenance $(-0.15 \%)$, construction and extraction $(-0.93 \%)$, arts, design, entertainment, sports and media $(-1.03 \%)$, manufacturing and production $(-1.63 \%)$ in which workers are being replaced by additive manufacturing and 3D printing, and significantly in office and administration $(-4.91 \%)$ where the employees will be soon redundant due to the common use of mobile internet, cloud technology, Big Data analytics and, again, the Internet of Things. Office job positions have little employment prospects. The World Economic Forum, in its report from 2018, forecasts that the companies should follow the trend and go towards the digitalization of business (Figure 2).

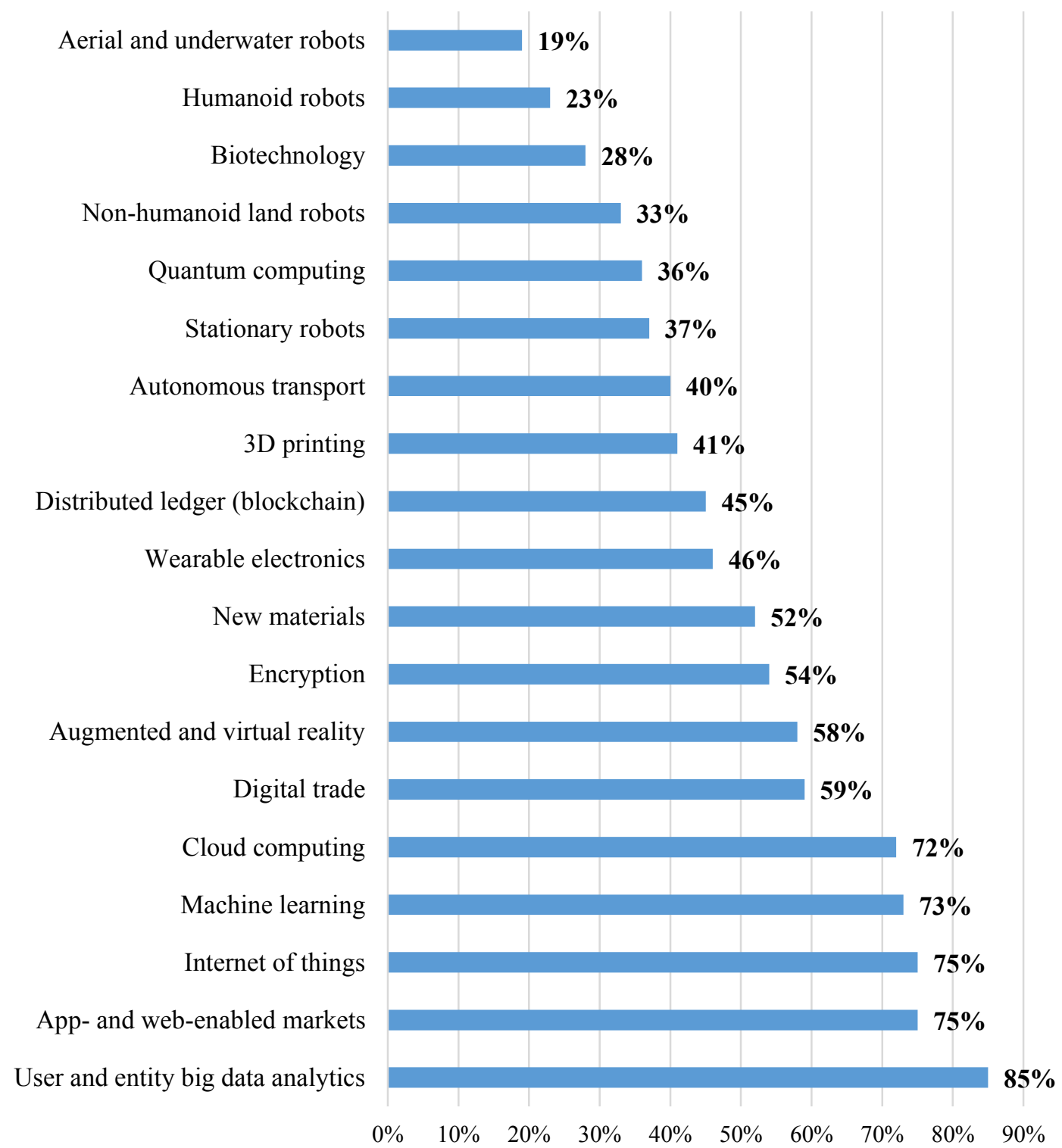

Figure 2. IT technologies to be likely in use by companies by 2022. Adapted from: "The Future of Jobs Report 2018" by The World Economic Forum. Copyright 2018 by Switzerland: World Economic Forum. 
According to the report, by $202285 \%$ of companies will adopt user and entity big data analytics, 75\% will adopt app- and web-enabled markets and Internet of Things. There will be $73 \%$ of companies that will implement machine learning, and $75 \%$ of companies will adopt cloud computing. Less than $60 \%$ and no more than $40 \%$ of companies should apply digital trade, augmented and virtual reality, blockchain and encryption, 3D printing or autonomous transport. Less than $30 \%$ of companies think of adopting stationary robots or humanoid and non-humanoid land robots, as well as quantum computing and biotechnology. The companies of the new era of technology and cyber systems will, therefore, be a chance for a career for employees with hard skills and specialized qualifications, who also have some soft skills such as the ability of adaptation, flexibility, mobility and ability to be fast-paced and continuously prepared for changes. According to the World Economic Forum (2018), almost 1 million jobs will vanish, but the new reality will gain 1.74 million new jobs (the survey included 15 million workers). The average hours of work performed by people will decrease from $71 \%$ in 2018 to $58 \%$ by 2022 , while the use of machines for this work will increase from $29 \%$ in 2018 to $42 \%$ by 2022 . $46 \%$ of tasks, including the processing and retrieval of information by machines, will also increase to $62 \%$ by 2022 . Tasks performed by people will be automated in such areas as communication and interaction (from $23 \%$ in 2018 to $30 \%$ by 2022); coordination, development, management and consultancy (from $20 \%$ in 2018 to $29 \%$ by 2022); reasoning and decision making (from 18\% in 2018 to 27\% by 2022) (World Economic Forum, 2018).

\section{Discussion}

The main goal of any production company is to streamline the production process and make it flexible and reduce the costs of manufacturing products on a massive scale. Implementation of technological innovations has, therefore, become an indispensable element of streamlining production processes. Thanks to computerization and automation of production, companies can increase the efficiency of the business by producing more and faster, improving the adjusting production to market expectations, as well as by responding to the changing preferences of customers more quickly (Strange and Zucchella, 2017; Dominici et al., 2016; Davis et al., 2012; Kamble et al., 2018; Groover, 2015). Digitization and computerization of the production give the company the possibility to adapt plans and strategies of manufacturing to customers. Pre-programmed networks of machines can produce goods much faster and according to demand at a given time rather than a man who needs to acquire new skills and experience, and requires more time to do the same work. Therefore, it is not surprising that more and more is being discussed about targeting the companies towards the cyber system. It allows streamlining the production process by significantly accelerating and changing the existing manufacture companies into so-called smart factories that will base their strategies on 
sophisticated cyber-machines, robots and computer systems managing, controlling and making autonomous decisions in a better and more efficient way that a human does (Wang et al., 2016; Santos et al., 2017; Schlaepfer et al., 2015; Lee et al., 2014, Lasi et al., 2014). Right now, in front of our eyes, there is the Fourth Revolution of Industry (Industry 4.0) going on that essentially relies on the interaction of human, machinery and production processes (AlmadaLobo, 2016; Drath and Horch, 2014). It introduces such new technologies as Internet of Things used to send huge amounts of data, supported by advanced techniques of processing, analysing and calculating these data sets, i.e. Big Data and Cloud Computing (Mostafa et al., 2019; Fatorachian and Kazemi, 2018; Mourtzis et al., 2016; Lee et al., 2014). The provision of cybersecurity is also of great importance in this respect. Involvement in the production processes of fully autonomous robots, as well as technologies such as additive manufacturing (3-D printing), virtual simulations, expanded reality and the integration of information systems is supposed to complement human work or replace it if it is necessary (Strange and Zucchella, 2017; Kane et al., 2015, Bonekamp and Sure, 2015). In many countries, automation of industry will force the public authorities, business executives, managers and leaders to develop completely new programs of education and training for adapting current employees to new working conditions aimed at cooperation and replenishment of machines. B. Frey and M.A. Osborne (2013) emphasize that the pace of technological innovations directly affects the labour markets, and the implementation of technology into production processes (and not only) causes dismissal of employees. What is more, the authors mentioned above pay attention to the fact that the technologies are not only part of the production processes, but also enter everyday life so strongly that such well-filled industries as transport and logistics can be fully automated, an example of which, according to the authors, is a tendency to market autonomous cars without a driver. Consequently, the work carried out so far by individuals' hands will be fully computerized and automated, so the work of human hands will become unnecessary in large part of the workplaces. M.O. Qureshi and R.M. Syed (2014) claim that employment drops will primarily affect developing countries and the work of the middle class. As an example, one can give the extensive automation of workstations for elevator operators or toll collectors for motorways. According to the authors, the companies will be looking for employees with specialist and higher qualifications. As said by E. Brynjolfsson and A. McAfee (2014), the future employee should acquire certain talents oriented to technics and IT as there will be a demand for specialists and scientists involved in data processing as well as experts in artificial intelligence, and such talents will be more valuable for the company and its production line than capital. Eventually, the labour market will be divided into groups of workforce less qualified and less paid, and the workforce of high qualifications and well, highly paid, and such segregation may result in social conflicts. Similar applications based on own analysis were introduced by D. Matovčíková (2017), who states that in 2016, over 60,000 employees were deprived of work at Foxconn, which, because of labour costs, substituted people with robots. The author also refers to research done in Great Britain, where it is assumed that about $30 \%$ of 
jobs can be liquidated in connection with the application of artificial intelligence solutions, which indicates that in 15 years over 10 million Britons may lose their employment in favour of robots.

\section{Conclusions}

The industry of the Fourth Revolution will surely bring about a lot of significant changes in HR management. There are many reorganizing challenges for companies, including solving the problem of potential job losses for a large number of employees. Certainly, these challenges will include the need to introduce a series of trainings adapting to new working conditions among the part of the crew that will be able to maintain their current positions, as well as help and support packages for people forced to look for new employment opportunities. New generations entering the labour market have a chance to adapt to the already existing changes. However, those workers who already function on the labour market are mainly at risk of losing their job due to lack of expected skills and knowledge, but also because of lack of qualities such as ability to adapt, self-esteem, and positive attitude to learning new issues and acquiring new qualifications. All the more so it can be difficult when it comes to obtaining skills in the field of IT technology, biotechnology, robotics and computer engineering, and the Industry 4.0 is mainly focused on such skills and knowledge. Indeed, many people will find their way into the new reality without a problem and will perceive the era of Industry 4.0 as an excellent opportunity for their development and career.

Nevertheless, attention should be paid to the fact that the threat of unemployment in many areas can be a massive problem for entire countries struggling with the ageing population, lack of appropriate conditions for education and training, lack of access to new technologies and so far oriented to work by human hands. Will companies introducing artificial intelligence, robots and cyber-machines to reduce production, labour and trade costs have ready-made solutions for employees? This question will probably be answered in time, when the fourth revolution gains momentum in all countries, including those less technologically advanced.

\section{References}

1. Almada-Lobo, F. (2016). The Industry 4.0 revolution and the future of manufacturing execution systems (MES). Journal of Innovation Management, 3(4), 16-21. doi: https://doi.org/10.24840/2183-0606_003.004_0003. 
2. Bonekamp, L., and Sure, M. (2015). Consequences of Industry 4.0 on Human Labour and Work Organisation. The Journal of Business and Media Psychology, 1, 33-40. Retrieved from https://journal-bmp.de/wp-content/uploads/2015/12/04_Bonekamp-Sure_final.pdf, 03.06.2019.

3. Brynjolfsson, E., and McAfee, A. (2014). The second machine age: Work, progress, and prosperity in a time of brilliant technologies. New York: W.W. Norton \& Company. Retrieved from https://edisciplinas.usp.br/pluginfile.php/4312922/mod_resource/content/ 2/Erik\%20-\%20The\%20Second\%20Machine\%20Age.pdf, 03.06.2019.

4. Davis, J., Edgar, T., Porter, J., Bernaden, J., and Sarli, M. (2012). Smart manufacturing, manufacturing intelligence and demand-dynamic performance. Computers \& Chemical Engineering, 47(20), 145-156. doi: https://doi.org/10.1016/j.compchemeng.2012.06.037.

5. Dominici, G., Roblek, V., Abbate, T., and Tani, M. (2016). "Click and drive": Consumer attitude to product development. Towards future transformations of driving experience. Business Process Management Journal, 22, 420-434. doi:10.1108/BPMJ-05-2015-0076.

6. Drath, R., and Horch, A. (2014). Industrie 4.0 Hit or Hype. IEEE Industrial Electronics Magazine, 8(2), 56-58. Retrieved from https://www.researchgate.net/profile/Rainer_Drath/ publication/263285662_Industrie_40_Hit_or_Hype_Industry_Forum/links/5909965e4585 15ebb495dde7/Industrie-40-Hit-or-Hype-Industry-Forum.pdf, 15.05.2019.

7. Fatorachian, H., and Kazemi, H. (2018). A Critical Investigation of Industry 4.0 in Manufacturing Theoretical Operationalisation Framework. Production Planning \& Control. The Management of Operations, 29(8), 633-644. doi: 10.1080/ 09537287.2018.1424960.

8. Frey, B., and Osborne, M.A. (2017). The future of employment: How susceptible are jobs to computerisation? Technological Forecasting and Social Change, 114, 254-280. doi: https://doi.org/10.1016/j.techfore.2016.08.019.

9. Groover, M.P. (2015). Automation, production systems, and computer-integrated manufacturing. New York: Pearson Higher Education, Inc. Retrieved from https://www.academia.edu/34819103/Automation_CIM_Groover_4th_Edition.pdf, 11.06.2019.

10. Kane, G.C., Palmer, D., Phillips, A.N., and Kiron, D. (2015). Is your business ready for a digital future? MIT Sloan Management Review, 56(4), 36-45. Retrieved from http://ilp.mit.edu/media/news_articles/smr/2015/56415.pdf.

11. Lasi, H., Fettke, P., Kemper, H.G., Feld, T., and Hoffmann, M. (2014). Industry 4.0. Business \& Information Systems Engineering, 6(4), 239-242. doi: https://doi.org/10.1007/ s12599-014-0334-4.

12. Lee, J., Kao, H.-A., and Yang, S. (2014). Service Innovation and Smart Analytics for Industry 4.0 and Big Data Environment. Procedia CIRP, 16, 3-8. doi: 10.1016/ j.procir.2014.02.001. 
13. Matovčíková, D. (2017). Industry 4.0 as the Culprit of Unemployment. 12th IWKM 2017, 12-13 October 2017, Trenčín, Slovakia, Retrieved from http:/www.cutn.sk/Library/ proceedings/km_2017/PDF_FILES/09_Matovcikova-71-78.pdf, 16.06.2019.

14. Mostafa, N., Hamdy, W., and Alawady, H. (2019). Impacts of Internet of Things on Supply Chains: A Framework for Warehousing, Social Sciences, 2019 8(3), 84, 1-10. doi:10.3390/socsci8030084.

15. Mourtzis, D., Vlachou, E., and Milas, N. (2016). Industrial Big Data as a Result of IoT Adoption in Manufacturing. Procedia CIRP, 55, 290-295. doi: 10.1016/j.procir. 2016.07.038.

16. Qureshi, M.O., and Syed, R.M. (2014). The Impact of Robotics on Employment and Motivation of Employees in the Service Sector, with Special Reference to Health Care. Safety and Health at Work, 5(4), 198-202. doi: 10.1016/j.shaw.2014.07.003.

17. Sachin, S.S., Gunasekaran, A., and Gawankar, S.A. (2018). Industry 4.0 framework: A systematic literature review identifying the current trends and future perspectives. Process Safety and Environmental Protection, 117, 408-25. doi: https://doi.org/10.1016/ j.psep.2018.05.009.

18. Santos, M.T., Oliveira e Sá, J., Andrade, C., Vale Lima, F., Costa, E., Costa, C., Martinho, B., and Galvão, J. (2017). A Big Data system supporting Bosch Braga Industry 4.0 strategy. International Journal of Information Management, 37(6), 750-760. doi:10.1016/ j.ijinfomgt.2017.07.012.

19. Schlaepfer, R.C., Koch, M., and Merkofer, P. (2017). Industry 4.0 - Challenges and solutions for the digital transformations and use of exponential technologies. Zurich: Deloitte AG. Retrieved from http://www.industrie2025.ch/fileadmin/user_upload/ch-endelloite-ndustry-4-0-24102014.pdf, 03.06.2019.

20. Strange, R., and Zucchella, A. (2017). Industry 4.0, global value chains and international business. Multinational Business Review, 25(3), 174-184. doi: https://doi.org/10.1108/ MBR-05-2017-0028.

21. The World Economic Forum (2016). The Future of Jobs. Employment, Skills and Workforce Strategy for the Fourth Industrial Revolution. Switzerland: World Economic Forum. Retrieved from http://www3.weforum.org/docs/WEF_Future_of_Jobs.pdf, 03.06.2019.

22. The World Economic Forum (2018). The Future of Jobs Report 2018. Switzerland: World Economic Forum. Retrieved from http://www3.weforum.org/docs/ WEF_Future_of_Jobs_2018.pdf, 04.06.2019.

23. Wang, S., Wan, J., Zhang, D., Li, D., and Zhang, C. (2016). Towards smart factory for industry 4.0: a self-organized multi-agent system with big data based feedback and coordination. Computer Networks, 101, 158-168. doi: 10.1016/j.comnet.2015.12.017.

24. World Bank (2019). World Development Report 2019: The Changing Nature of Work. Washington DC: World Bank. doi:10.1596/978-1-4648-1328-3. 